\title{
“EN BUENA MEDIÇINA". LAS FUENTES MÉDICAS DEL DISCURSO DE CÉSPEDES ANTE LA INQUISICIÓN
}

\author{
Paloma Moral de Calatrava \\ Departamento de Enfermería. Universidad de Murcia \\ pmoral@um.es \\ ORCID iD: https://orcid.org/0000-0001-9061-111X
}

Recibido: 14 febrero 2018; Aprobado: 4 julio 2018.

Cómo citar este artículo/Citation: Moral de Calatrava, Paloma (2018), "En buena mediçina". Las fuentes médicas del discurso de Céspedes ante la Inquisición", Asclepio, 70 (2): p230. https://doi.org/10.3989/asclepio.2018.14

RESUMEN: Uno de los hermafroditas más afamados del siglo XVI español fue Céspedes, un cirujano que trató de persuadir a la Inquisición de que la doble mutación corporal que sufrió era un proceso natural. Céspedes afirmó que la transformación de Elena comenzó cuando dio a luz y fue completada mediante cirugía, pero Eleno volvió a su forma femenina de nuevo en la cárcel, porque un cáncer le forzó a cortarse el pene. En este trabajo estudio el testimonio de Céspedes conocido por la historiografía como el 'discurso de su vida', analizo los argumentos que utilizó para convencer al tribunal de sus transmutaciones consecutivas de acuerdo a su biblioteca e identifico los tres textos médicos en romance en los que se basó.

PALABRAS CLAVE: Céspedes; hermafroditismo; cirugía; continuum sexual; historia de género.

\section{“EN BUENA MEDIÇINA". CESPEDES' MEDICAL SOURCES DURING THEIR DEPOSITION BEFORE THE INQUISITION TRIAL}

\begin{abstract}
One of the most famous hermaphrodite in Spain's sixteenth Century was Céspedes, a surgeon who tried to persuade the Inquisition court that the double corporal mutations (s)he suffered were a natural process. Céspedes state that the Elena's transformation started when she gave birth and was completed by surgery, but Eleno became into a female shape again in prison, because a cancer forced him to cut himself the penis. In this paper, I study Céspedes' deposition, known by historiography as the "discourse of her life", I analyze the arguments (s)he used in order to convince the court their consecutive transmutations according their medical library, and I identify the tree vernacular medical texts (s)he based on.
\end{abstract}

KEY WORDS: Céspedes; hermaphroditism; surgery; sexual continuum; Gender History. 


\section{INTRODUCCIÓN}

“(...) como fue el [caso] que sucedio en Castilla, con aquella esclaua Andaluça, Ilamada Elena de Cespedes, la qual dexado el habito de muger, fingio muchos años ser hombre, y mostraua serlo, aunque mal tallado y sin barba concierto artificio, que traya puesto para cumplir con mugeres, y era tan al natural, que despues de auerle mirado algunos cirujanos, y declarado ser hombre, se caso en CienPoçuelos, lugar del Conde de Chinchon. Pero al fin supo el santo Oficio de la Inquisicion la verdad del caso, y descubrio el engaño que auia, y assi dize que pudo auerle en los que estan referidos" 1 .

Cuando el médico Jerónimo de Huerta tradujo la Historia Natural de Plinio en 1599 añadió en cada capítulo un comentario que le permitía mostrar la distancia entre el pensamiento antiguo y el del siglo XVI (Moure 2008, 222), y el caso Céspedes ilustra este propósito, porque si Plinio tenía por verdaderos los casos de mujeres que habían cambiado de sexo, Huerta sostenía que se debían a un engaño femenino. Hubo otros casos y las acusadas ofrecieron explicaciones diversas (Zamora 2008; de la Rosa y Martín 2016); si la monja italiana Benedetta Carlini arguyó que el ángel Splenditello "poseía" su cuerpo cada vez que mantenía relaciones sexuales con su compañera del monasterio (Brown 1986, 119; Brown 1990)², Céspedes se basó en sus estudios de cirugía y en la filosofía natural para afirmar que parir a su hijo fue el inicio de una transmutación que completó quirúrgicamente y que, después, montar a caballo le había provocado una enfermedad que le obligó a cortar progresivamente su propia verga mientras estaba en la prisión de la Inquisición.

La historiografía sobre el caso Céspedes ha tratado el tema de forma plural; mientras que algunos han hecho hincapié en la compleja articulación entre la teoría científica y las normas sociales de la época, otros han analizado las implicaciones de los médicos que examinaron su cuerpo, o han estudiado los argumentos de fiscales, testigos y la defensa. Barbazza afirmó que el hecho de que Céspedes se vistiera de hombre se debió al frustrado esfuerzo de integración y aceptación social de una lesbiana, una idea que reiteró posteriormente arguyendo que la Inquisición impuso a Céspedes una identidad sexual utilizando la medicina (Barbazza, 1984 y 2014). Burshatin explicó la insistencia del discurso de Céspedes sobre su naturaleza hermafrodita de acuerdo a la filosofía natural de la época (Burshatin 1996), un enfoque que Vázquez y Cleminson retomaron considerando la importancia del discurso científico para la comprensión social del hermafroditismo (Cleminson y Vázquez 2009; 2016; Vázquez y Cleminson 2010). En ese trabajo analizaron los resultados dispares de cuatro casos de hermafroditas en los que se oyen voces eclesiásticas, literarias e intelectuales, y puede comprenderse hasta qué punto la teoría ilustrada fue insuficiente para la aceptación de realidades sexuales diferentes a la norma heterosexual. Céspedes llevó una vida caracterizada por continuos traslados de residencia, cambios de apariencia física y oficios que se interpretan como las distintas estrategias de una mujer por reinventarse a sí misma en busca de su identidad, algo que se desarticuló definitivamente cuando trató de conseguir la legitimidad social a través del matrimonio. Para Martín Casares y Díaz Hernández (2016), Céspedes no cejó en su empeño de libertad sexual en un mundo jerárquicamente ordenado en dos sexos y dos géneros, y el resultado de ese esfuerzo fue la obligación de definirse como mujer (Franco, 2012; Hessel, 2015).

Vázquez (2011) aclaró que la transexualidad no fue una categoría sexual en la Edad Moderna y pretender traspasar los límites de apariencia, comportamiento y anatomía -como hizo Céspedes- era un ejercicio imposible. Desde esta perspectiva es posible comprender por qué en el interrogatorio preguntaron por los detalles más íntimos de las relaciones sexuales entre Céspedes y María del Caño, su esposa. Según Molina (2015) la orientación falocéntrica del coito impulsó al fiscal una y otra vez a preguntar por el instrumento utilizado en la penetración, mientras que Céspedes y María negaron su uso. El interrogador seguía una mentalidad sexual dualista, pero el matrimonio sabía que confirmar el uso de cualquier utensilio suponía ratificarse como sodomitas y exponerse a la pena capital (Eisenberg 1990; Puff 2000, 46; Beteta 2009, 229; Velasco 2011, 16-17; Rolker 2014, 217-218). A pesar de que la transexualidad es una categoría sexual hoy en día, algunos médicos contemporáneos que han analizado el caso llegan a la misma conclusión que el tribunal de la Inquisición, y consideran que Céspedes era una mujer (Carrillo et al. 2015). Otros destacan el papel de Francisco Díaz, cirujano de Felipe II, que avaló la potencia y virilidad de Céspedes tras su primera inspección genital; un diagnóstico del que tuvo que retractarse afirmando que era una mujer completa y cumplida (Maganto, 2007a; Maganto 2007b).

Cuando Francisco Díaz reconoció por primera vez a Céspedes ya había escrito un compendio de cirugía al que le añadió un breve tratado con cuatro enfermedades raras, y la primera fue la nimphea que consideró una anomalía de los genitales femeninos "porque es 
un crescimiento de carne, que sale por el pudendo de la mujer, con pesadumbre de la que lo padesce, y aun con espanto y sospecha de quien lo mira" ${ }^{3}$. La complejidad diagnóstica residía en un comportamiento equivalente entre la nimphea y la verga, porque se hinchaba y erguía endurecida. La enferma no podía esconder su afección tras la ropa y, al escándalo público, se le añadían la imposibilidad de mantener relaciones carnales con un hombre y ser madre. Aunque era una alteración excepcional, el cirujano tuvo suerte y afirmó haber atendido a tres mujeres: dos monjas y una casada. El tratamiento de Díaz se dirigía a contener el desorden social y devolver a los genitales una forma conveniente para la consumación porque el cirujano sólo operó a la casada. El confinamiento de las religiosas mantenía enclaustrado el escándalo público y estas mujeres no precisaban la "creación" de unos genitales funcionales.

\footnotetext{
"las nimphas que diximos arriba crescen algunas vezes de manera que quien no entiende lo que es, paresce miembro viril: porque se alça y entiessa, que, tocando a la ropa se desuella cosa de gran verguença, e escandalo y plaga, de gran lastima: porque tienta extrañamente, a la que lo padesce, a la luxuria, lo qual acontesce endonzellas libidinosas y luxuriosas, porque e visto dos monjas en un monesterio, padescer este afecto. Y también a una casada que le salía mas de quatro dedos por su natura, y se le alçaua y alçandosele, la atormentaua, fue tanto el desseo que tenia deparir, que teniendo aquello por impedimento, se puso en cura, y yo se lo cure, y sano muy bien, que después pario tres vezes" ${ }^{\prime \prime}$
}

La supuesta experiencia de Francisco Díaz en estos casos le convertían en un examinador idóneo y confirmó la masculinidad de Céspedes, pero cuando la Inquisición decidió que era una mujer volvió a llamarlo para saber si había sido sobornado. Se han analizado las estrategias que Céspedes desarrolló a lo largo de su vida para modelar su cuerpo e integrarse socialmente, o cómo se utilizó la medicina para imponerle un sexo, un género y una identidad sexual, aunque todavía no se han identificado las fuentes médicas que utilizó para construir su defensa. Cuando el juicio se celebró ya era un cirujano experimentado y poseía una biblioteca médica con libros en romance. Como demostraré, Céspedes se definió andrógino basándose en tres textos médicos que tenía en castellano. Su empeño en obtener el reconocimiento social como hombre muestra que en la España del siglo XVI convivían dos visiones sobre el hermafroditismo: de un lado, la teoría médica medieval sobre el continuum sexual; de otro, la renacentista, que sólo aceptaba la androginia biológica como una posibilidad teórica y necesitaron identificar cada caso con un sexo y un género. Medicina y cambio son términos fundamentales en la vida de Céspedes: aprendió y ejerció la cirugía, afirmó que una intervención quirúrgica transformó su sexo y que, consecuentemente, cambió de identidad sexual; pero los médicos de la Inquisición le impusieron otra. Céspedes no sólo se mudó con frecuencia de domicilio o transmutó de mujer a hombre, sino que ante la Inquisición sostuvo que era de nuevo una mujer por un cáncer genital. La primera parte de este trabajo aborda las circunstancias y argumentos esgrimidos en el juicio, a lo que hay que sumar que, en la España del siglo XVI, convivían diferentes teorías médicas del hermafroditismo que se analizan a continuación. En un momento en el que la propia teoría médica sobre los andróginos estaba cambiando, convivieron textos de raigambre medieval con postulados anatómicos renacentistas y patrones culturales de dualismo sexual. La tercera parte de este trabajo identifica los textos que Céspedes utilizó para la construcción de su defensa. Cuando nació no le pusieron un nombre y cuando murió la mujer a la que cuidaba heredó el suyo. Después eligió llamarse Céspedes sin identificarse con un sexo o un género, de modo que este trabajo respeta esta decisión y mantiene, en lo posible, el género neutro. Este caso se conserva en el Archivo Histórico Nacional de Madrid bajo el título "Elena de çespedes alias Eleno de çespedes. Çirujano Hermafrodita" (AHN, Leg. 234, n. 24), carece de foliación completa y tiene la acostumbrada división en tres cuadernillos de los procesos inquisitoriales, por lo que en las citas textuales me referiré tan sólo al cuadernillo en el que se encuentra.

\section{LA METAMORFOSIS VITAL}

Céspedes nació en Alhama de Granada hacia 1545 y cuando el juicio se celebró tenía poco más de 40 años. Su madre era una esclava negra de Benito de Medina y, aunque afirmó que su padre era un labrador, algunos historiadores sostienen que es presumible que fuera hija biológica del amo materno (Burshatin 1999, 422). Como era costumbre con los esclavos, marcaron sus mejillas con hierros candentes para identificar a su dueño, pero en el juicio afirmó "que no ha sido esclava de nadie" (Maganto 2007a, 21). Cuando falleció la esposa de su amo heredó su nombre, fue manumitida, regresó con sus padres y aprendió a leer. Se concertó su matrimonio "con Xpoval Lombardo, alvañil vecino de Jaen, conel qual hizo vida maridable tres meses y tuvo un hijo 
que de presente es bivo, conel qual hallandose mal diçe absente" ${ }^{5}$. Embarazada y abandonada volvió a Alhama hasta la muerte de su madre, se trasladó a Sevilla y allí dejó a su hijo al cuidado de un vecino. Parece que nunca volvió a verle, ni siquiera durante el juicio. Hacia los 20 años se mudó a Granada, trabajó como calcetera y aprendió sastrería, pero unos meses después volvió a trasladarse. En San Lúcar de Barrameda conoció a Ana de Albanchez, la mujer por la que acudió a un cirujano que diagnosticó el hermafroditismo y realizó la intervención; la única persona que dijo conocer su naturaleza doble. Año y medio después se trasladó a Jerez de la Frontera, donde mantuvo una violenta disputa que le acarreó su primer encarcelamiento, así que para evitar la venganza que le habían prometido "determino de andar en habito de hombre y dexo el de muger que hasta alli auia siempre traydo" ${ }^{\prime \prime}$.

Hasta ese momento su metamorfosis era personal, porque había pasado de esclava a libre, había sido madre y diagnosticada de hermafroditismo, había pasado de vestir como una mujer a ataviarse como un varón, se había operado y convertido en un hombre. Con una nueva condición social, una identidad recién estrenada y la indumentaria apropiada pasó a llamarse simplemente "Çespedes sin decir Pedro, ni Eleno, ni Juan"7. Tras las transformaciones personales se alejó de las ciudades y trabajó como mozo de labranza y pastor, pero le tomaron por uno de los moriscos sublevados de la sierra de las Alpujarras y volvió a la cárcel. Un vecino de Alhama reconoció a Elena de Céspedes mientras visitaba el penal de Arcos e intercedió ante el corregidor y "este la solto y la mando poner ensu habito de muger" . Lo que pasó después formó parte de la defensa que Céspedes desarrolló en el juicio, porque afirmaba que, si como Elena se había casado y había tenido un hijo, como hombre mantuvo un escandaloso comportamiento sexual, ya que vestir de mujer no detenía su deseo por las mujeres. Al salir de prisión entró al servicio de un párroco de Arcos y simultaneó relaciones carnales con una hermana de éste y una vecina de la ciudad. Por eso Céspedes afirmó "que si se auia casado con muger fue por verse con miembro de hombre, y que como tal podia tener acceso a muger. Y que como andaua con muchas quisso por salir de pecado, casarse y no tener quenta mas que con su muger, y que por esto se auia casado y no penso que enello erraua" ${ }^{\prime \prime}$.

La transformación, sin embargo, no era completa y a Céspedes le faltaba el refrendo social como hombre y, por eso, cuando "Se començaron a leuantar los moriscos de granada, aquesta determino de hir a la guerra paraloque boluio adejar elauito de muger y sepuso otra vez el auito de hombre llamandose siempre Çespedes"10. Se enroló dos veces, pero cuando regresó la primera vez fue a Jerez a examinarse para ejercer legalmente la sastrería. En la ciudad que le llevó a la cárcel mientras todavía vestía como mujer obtuvo el título de "sastra", aunque en Arcos su indumentaria ya era masculina. Después inició un peregrinaje por Andalucía que duró seis años, hasta que decidió ir a Madrid hacia 1575 "y usando alli el dicho officio, tomo amistad con un valenciano çurujano y la lleuo a su casa por huesped y la començo a dar liciones de curar, y dentro de pocos dias curaua tanbien con el"11. Con una educación que consiguió por un sistema abierto (García Ballester 2001, 213-225), Céspedes ejerció tres años la cirugía en el hospital de la corte y, después, dos más en la sierra madrileña, hasta que le acusaron de practicar sin licencia. Se examinó y obtuvo dos títulos; uno para sangrar y purgar, y otro de cirujano. Céspedes siguió su peregrinaje y ejerció en distintos pueblos de Madrid, Cuenca y Toledo, pero conoció a María del Caño y decidió casarse. Éste fue el último intento por conseguir la aprobación como hombre de sus coetáneos.

En la segunda mitad del siglo XVI ya se habían fijado los impedimentos y el procedimiento matrimonial (Moral de Calatrava 2009, 242-250), y el 20 de diciembre de 1584 Céspedes inició los trámites ante el vicario general de Madrid afirmando que era libre y soltero. Pero "porsu aspecto pareçia ser capon [y el sacerdote] le pidio declarase si lo hera y mando que diese ynformacion"12. El examen físico lo realizaron unos hombres inexpertos que acreditaron que era hombre y se anunció el nuevo matrimonio. Sin embargo, se presentaron dos impedimentos al aparecer "personas diçiendo que teniados sexos, y por una Ysabel ortiz diçiendo que estaba casada conel y que la auia dado palabra de casamiento"13. La alegación de esta mujer no prosperó porque el compromiso era privado y no habían iniciado los trámites matrimoniales, aunque las dudas públicas sobre si era un hombre cuajaron y el vicario ordenó que Antonio Mantilla y Francisco Díaz inspeccionasen su cuerpo. Para evitar la exploración de médicos reputados solicitó que se realizase en Toledo, aunque nunca llegó a esa ciudad y se detuvo en Yepes donde diez testigos - entre los que estaban el médico y el cirujano de la ciudad- volvieron a certificar que era hombre. Volvió a Madrid y mostró este informe, pero el vicario insistió en el examen de Matilla y Díaz que refrendaron así su masculinidad: 
"Desposiciones de los susodichos en la villa de madrid, en ocho dias del mes de febrero de mil e quinientos e ochenta e seis años ante el dicho señor doctor Juan Bautista Neroni, vicario general enla dicha villa. Compareçio presente el doctor antonio mantilla, medico residente enesta corte, el qual fue primeramente Reçibido juramento en forma de derecho y auiendo le hecho dello que elauisto al dicho Eleno de çespedes quees el que parecia ser antesu merced, y ansimismo lea visto por vista de ojos sus partes naturales y el miembro viril, el qual tiene bueno y perfecto con dos testiculos. Y en lo demas solo leavisto una berruga enla aRimada al ano, la qual dice el dicho Eleno quele quedo deser apostema que tubo, pero no avisto cosa que penetre ni tiene cosa deser confemenil, y asimismo lo atocado y non perçibido con el ta(c)to cosa. Y despues del susodicho, enla dicha villa de madrid, a diez y siete dias del mes defebrero de mil e quinientos y ochenta y seis años, el dicho doctor Juan Bautista neroni, vicario general enla dicha villa, pareçio el doctor francisco diaz, medico y çirujano desu magestad, del qual fue rescibido juramento en forma de derecho. Y auiendosele presente siendo preguntado delo queavisto al dicho Eleno de çespedes e que es el mesmo que vido enpresençia desu merçed, y que es uerdad que lea visto sus miembros genitales y las mas partes viçinas por vista de ojos, y tocadole con las manos. $Y$ que declaraua e declaro que el tiene miembro genital, el qual es bastante y perfecto consus testiculos formados como qual quiera hombre. Y que enla parte ynferior junto al ano tiene una manera de aRugacion que, a su parecer, alo que toco y visto no tiene semejanza de cossa que pueda presumirse ser natural, por que procurandole tocar no pudo ni fue posible allarle perforaçion alguna que se pudiese presumir tal cossa. Y ansi dixo e declaro que suparecer notiene semejaça de erma fisilta (sic) ni cossa dello y que estaes la uerdad parael juramento que hiço. Y firmado desu nombre el doctor diaz ante $\mathrm{mi}^{\prime 14}$.

Céspedes y María del Caño se casaron en 1586 y se trasladaron a Ocaña porque no había cirujano. Allí, tras la denuncia de un antiguo compañero de armas, se abrió un juicio civil a mediados de junio de 1587. El tribunal de la Inquisición de Toledo reclamó el caso en julio porque los delitos eran de su jurisdicción: menosprecio del sacramento matrimonial por bigamia, herejía, pacto demoniaco, soborno a testigos y mentir al reiterarse como hermafrodita. La Inquisición investigó durante cinco meses y, aunque dictó sentencia en noviembre de 1587 contra de Elena de Céspedes, tardaron más de un año en cumplirla. Céspedes siempre se definió como hombre, pero la Inquisición dictaminó que era una mujer y la condena incluía salir a la plaza pública vestida de penitente, abjurar de levi, recibir cien azotes en Toledo y otros tantos en Ciempozuelos, y pasar diez años sirviendo en un hospital. Su fama entre los toledanos - quizá por su hermafroditismo o por curar gratis- provocó que los enfermos acudieran en tropel y del Hospital del Rey la trasladaron al de San Lázaro. Pero su presencia seguía provocando "muchos inconvenientes porque abiendo cobrado nombre de que la susodicha es cirujano y que cura muchas enfermedades, es tanta la gente que acude a ella que no la dejan cumplir con quietud su reclusion"15. En marzo de 1589 la enviaron al hospital de Puente del Arzobispo y allí se le pierde la pista (Ruiz Rodríguez y Hernández Delgado 2017).

\section{NATURALMENTE DISRUPTIVO: LAS TEORÍAS MÉDICAS DEL HERMAFRODITISMO}

"E lo que pasa es que como en este mundo muchas veçes se an vjsto personas que son androginos, que por otro nonbre se llaman hermafroditos, que tienen entramos sexos, yo tambien e sido uno de estos"16.

El 17 de noviembre de 1587, dos días antes de que el tribunal de la Inquisición emitiera sentencia, Céspedes se ratificó como hermafrodita, aunque también afirmó que no lo había sido siempre. De hecho, no lo era en ese momento y utilizó el tiempo verbal en pasado. Aunque meses antes Francisco Díaz había confirmado sus aptitudes masculinas para casarse, los peritos inquisitoriales hicieron una nueva inspección para comprobar si tenía los genitales de un hombre y concluyeron que era una mujer. Las causas del hermafroditismo no estaban claras y se especulaba con dos teorías: la primera entendía que el sexo del recién nacido se debía a la "lucha" entre la semilla paterna y la materna, lo que suponía reconocer que las mujeres tenían un "semen" con capacidad para generar y modificar el sexo del embrión que fue el núcleo de la teoría del espejo invertido; la segunda afirmaba que el entorno uterino determinaba los genitales de la criatura según el lugar en el que se desarrollaba, una explicación que hoy se conoce como la teoría de las siete celdas (Siraisi 1990, 91-96; Moral de Calatrava 2007, 208; Moral de Calatrava 2008b, 83-97).

Cuál era la contribución femenina al embarazo fue controvertido, porque si Aristóteles sostuvo que la sangre menstrual era la materia estéril sobre la que actuaba la fértil semilla paterna, Galeno defendía la equivalencia estructural y funcional de los genitales masculinos y femeninos, aunque los de las mujeres estaban invertidos. Galeno sostenía que Aristóteles se equivocaba cuando afirmó que las mujeres no tenían "simiente" y que la sangre menstrual era una materia 
fetal pasiva sobre la que actuaba el semen paterno dotándole de vida y forma humana (Moral de Calatrava 2006). Ya en el XIII, intelectuales como Alberto Magno o el castellano Juan Gil de Zamora fracasaron intentando armonizar ambas posturas, y concluyeron que de la fuerza y cantidad de semen que el matrimonio debía emitir al unísono resultaba una mezcla que determinaba el sexo, el comportamiento y la orientación sexual ${ }^{17}$ (Moral de Calatrava 2009, 251-253; de Asúa 2013). La idea galénica de los genitales invertidos se mantuvo en el siglo XVI, y en las ediciones romances de la Cirugia Magna que el influyente Guy de Chauliac redactó en latín en 1363, puede leerse que la matriz "es assi como verga reuersada: o dentro, puesta en el XIIII de vtilitate particularum"18. La correspondencia anatómica testículos-ovarios, pene-vagina, escroto-útero de Galeno implicaba aceptar que las mujeres poseían testículos internos, que tenían esperma y que, como los hombres, expulsaban su semilla en el clímax. De ahí que algunos médicos ya aconsejaran en el XIV que los hombres excitaran sexualmente a su compañera (Connell 2000, 421; Moral de Calatrava, 2008a).

Si la teoría del espejo invertido se formuló en la Antigüedad, la de las siete celdas cristalizó en la Edad Media en un tratado falsamente atribuido a Galeno -De Spermate- y, a pesar de las evidencias en contra, muy pocos negaron la división uterina (Merisalo y Pahta 2008). Incluso Mondino de Liuzzi, tras realizar las primeras necropsias femeninas en 1315 , sostuvo que "concauitas vero eius habet septem cellulas, tres in parte dextra: et tres in parte sinistra: et vnam in summitate sive in medio eius"19 (Fonahn 1922, 41; Green 2011, 361). Aunque Vesalio negó en 1543 la compartimentación del útero, la teoría de las siete celdas era útil porque explicaba el hermafroditismo y, por eso, se mantuvo en las ediciones renacentistas de textos para médicos, cirujanos y parteras ${ }^{20}$. De hecho, los cirujanos romancistas del siglo XVI como Céspedes leían que en la celda donde se implantaba el embrión influía en su sexo, y que las mujeres podían modificarlo dependiendo de la postura que adoptaran después del coito. Así lo expresó Ketham a finales del siglo XV:

\footnotetext{
"Porque, como dize Alberto, las mujeres que, despues del ayuntamiento, se acuestan sobre el lado derecho salen preñadas de fijos, e las que se acuestan sobre el lado yzquierdo de fijas? Responde: por que los mestruos que estan reclusos corren a la parte de donde yaze la madrigera" ${ }^{21}$.
}

En los siglos XV y XVI, la influencia de Galeno y Aristóteles todavía era intensa, pero también la de las autoridades medievales, y los médicos mezclaron li- bremente evidencias modernas con argumentos propios de otras épocas. Por ejemplo, Ketham afirmó que el útero contenía siete celdas perpetuando la teoría pseudo-galénica medieval y, al tiempo, defendió que la contribución femenina era la sangre menstrual de acuerdo con Aristóteles ${ }^{22}$. El español Bernardino Montaña, por su parte, negó la división uterina apoyándose en Vesalio y mantuvo la idea medieval de que la leche materna provenía de la sangre menstrual gracias a "las venas que van ala madre [y que] suben al pecho", pero no tenía claro si las mujeres tenían se$m^{23}{ }^{23}$. Así expresó la confusión que había en la medicina española renacentista sobre la aportación femenina al embarazo y la suya propia:

"Ay tantas opiniones acerca de esto que nunca acaba de verificarse si la simiente de la muger sirue como materia, o como efficiente en la generacion de la criatura, o como materia y efficiente, como dizen algunos, o si es cosa impertinente a la generacion de la criatura, como dizen otros, sin argumentos. Lo que me paresce acerca dello es, que la simiente de la muger no es necessaria para la generacion de la criatura, porque bastan la sangre venal y arterial de la muger y la simiente del varon, pero como la simiente de la muger sea sangre arterial cozida en alguna manera mas que la sangre si acaesce venir a mezclarse con la simiente del varon alguna simiente de la muger, esta puede seruir como la sangre arterial y mucho mejor pues que se engendra della por mejor cozimiento" 24 .

La descripción anatómica que Vesalio hizo del útero no aclaraba las causas del hermafroditismo y los médicos del XVI recurrieron a la explicación que Alberto Magno ofreció en el siglo XIII. El dominico afirmó que una acumulación excesiva de sangre menstrual se oponía a la potente virtud formativa del semen paterno, provocando la aparición de dos genitales y la confusión de género. Para averiguar el sexo predominante debía estudiarse la complexión general porque si en los hombres predominaba el calor, las mujeres eran frías, y después podía operarse. La intervención debía hacer coincidir el sexo con el género, pero algunos casos eran confusos, como demostraba el que recogió en su De animalibus. Una niña nació con la vulva aparentemente "cerrada" por una piel y sus padres decidieron operarla para "hacerla apta" para el matrimonio, el coito y la gestación, pero en la cirugía feminizadora brotaron dos testículos y una verga, resultando ser varón y capaz de procrear.

\footnotetext{
"In quodam etiam nostri temporis nato testiculi infra pellem contenti erant superius, ita quod prominentia eorum repraesentabat duo labra vulvae muliebris: et fissura videbatur esse in medio clausa per
} 
pellem: et cum putaretur esse puella a parentibus et deberet aperiri fissura ut habilitaretur ad coitum, incisione facta prosilierunt testiculi et virga: et postea duxit uxorem et genuit ex ea plures filios" ${ }^{\prime 25}$.

En el siglo XVI, algunos médicos sostenían que el útero estaba dividido en siete celdas y otros que era una imagen especular de los genitales masculinos, pero ambas corrientes postulaban que en la matriz existían diferentes temperaturas que influían en el sexo fetal, y si en la cálida parte derecha se generaban varones, la izquierda era fría y formaba niñas. Entre ambas había un descenso gradual de temperatura, y en la templada franja intermedia se desarrollaban hermafroditas y homosexuales. El calor y el lugar eran fuerzas que afectaban al sexo y la sexualidad, pero la dualidad genital de los hermafroditas se percibió como un accidente biológico socialmente disruptivo (Cadden 1993, 170-1 y 212), porque en las relaciones sexuales al tener "el uno e el otro $\mathrm{mj}$ embro complido (...) puede fazer e padesçer" ${ }^{\prime 26}$. La medicina medieval fue más allá de un sistema dual de sexos y géneros, y concibió un espectro sexual natural que abarcaba desde las virago a los afeminados, pero en el Renacimiento, el carácter subversivo del hermafroditismo debía ser reprimido y ordenado mediante cirugía (MacLehose 2006, 672).

\section{LA METAMORFOSIS FÍSICA: CONSTRUCCIÓN Y REFU- TACIÓN DE UNA TEORÍA}

"y questa se fue aun liçenciado, Tapia, çurujano de aquella ciudad, el qual vio aquesta en secreto y la dixo que hera hermafrodito. Y con una tienta que metio dio aquesta una nabajada mas arriba delpellejo que avia empeçado a Romperse. Y dada la nabajada salio un miembro de hombre que señalo de el largo de una $\operatorname{secma}^{27}(\ldots)$.

$Y$ salio encorbado, un poco hecho en arco. $Y$ cortole el dicho zurujano un frenillo ${ }^{28}$, con esto quedo dicho miembro derecho. $Y$ dixo aquesta que tenia mal fundamento porque hera muy floxo en la Rayz y curo aquesta, y en quince dias la dio sana y aquesta quedo con abtitud depoder tener quenta con muger. Y bolvio a la dicha Ana de Albanchez y con ella tubo muchas veçes quenta y abtos como hombre"29.

El 17 de julio de 1587, Céspedes contó por qué y cómo se había transformado su cuerpo. Todavía vestía como mujer y ejercía la sastrería cuando intentó mantener una relación con Ana de Albanchez, la esposa del hombre para el que trabajaba. El pene oculto parecía desear a Ana, pero, "Aunque estaua alterada y tenia aquella caueza salida como tiene dicho, y se hecho ençima de ella, no la pudo haçer nada mas de aquella demostraçion" ${ }^{\prime 30}$. Tras este intento erótico frustrado recurrió a una cirugía que convirtió en elemento clave de su defensa. Reconoció que cuando era mujer había vestido como varón para protegerse de unos criminales, pero sostenía que tras la intervención era el atuendo adecuado porque era un hombre. Como cirujano sabía del estrecho vínculo entre las alteraciones de la anatomía genital y el hermafroditismo, y construyó un discurso basado en la teoría médica. Entre sus pocas y vetustas posesiones destaca una ecléctica biblioteca de veintisiete libros, la mayoría tratados de medicina que "compró a un licenciado todos juntos" (Maganto 2007a, 88). Tenía tres ejemplares en romance: el Libro de la Anothomia del Hombre de Bernardino Montaña, un texto de manufactura renacentista; la Cirugía Magna de Chauliac, que todavía era influyente en la formación quirúrgica, aunque fuera redactado en el siglo XIV; y el conocido Compendio de la Humana Salud de Ketham ${ }^{31}$.

La posesión de estos libros no fue mera apariencia y Céspedes los había leído, comprendido y memorizado. El uso de la palabra "frenillo" en su declaración no fue inocente. El vocabulario anatómico en romance carecía de una terminología fija en el XVI y, antes de que se celebrara este juicio, tan sólo Montaña (1551), Valverde (1556) y Fragoso (1581) usaron ese vocablo para referirse a lo que hoy conocemos como frenillo prepucial (García Jaúregui 2010, 225). Así que, para dar credibilidad a su discurso de defensa y demostrar sus conocimientos, Céspedes utilizó tecnicismos que conocía por la obra de Montaña para identificar el lugar exacto de la segunda incisión ${ }^{32}$.

Explicar la intervención quirúrgica también fue una estrategia intencionada, porque declaró que el cirujano hizo dos cortes: el primero permitió la salida de los genitales ocultos, y el segundo corrigió el pene curvo, una intervención que coligió de la Cirugía Magna de Chauliac. A diferencia de la medicina renacentista, la cirugía de los siglos XIII y XIV no participó en un pensamiento sexual de dos sexos opuestos e incompatibles (Rosenthal 1978, 55), sino que comprendió que los hermafroditas eran seres neutros dentro de un continuum ${ }^{33}$, y la defensa de Céspedes muestra esta concepción medieval fluida sobre el sexo y la sexualidad. Pese a que los andróginos fueron casos extraordinarios, los canonistas del XII trataron de responder cuestiones prácticas que, presumiblemente, no se plantearon en la vida cotidiana. Por ejemplo, Huguccio propuso en su Summa decretorum de 1190 asignar a los andróginos adultos un género según su comportamiento público y caracteres sexuales secun- 
darios como la barba. Pedro Cantor, por su parte, prohibió en la Summa de sacramentis (1189-1190) que el hermafrodita que se hubiera casado como hombre y enviudara, pudiera casarse después como una mujer (Rolker 2014, 195-196).

La cirugía medieval participó en esa corriente de plantearse problemas hipotéticos y ofrecer soluciones prácticas, y recomendó verificar la funcionalidad de la verga antes de intervenir (Green 2008, 97). Al tiempo, admitió la posibilidad teórica de casos inoperables de mujeres con penes y hombres con un agujero entre los testículos, "assi como coño de muger (...) por el qual echan la orina" ${ }^{34}$. Chauliac aconsejó a los cirujanos prudencia para no seccionar la salida de la orina, pero no describió los pormenores de la intervención ${ }^{35}$. Sin embargo, el orden de los capítulos sobre la cirugía genital del cirujano francés responde a esta concepción sobre la fluidez sexual y de género. Entre el hombre masculino y la mujer femenina, Chauliac admitió la posibilidad de dudar de la virilidad de un hombre por un exceso de piel que impedía el coito, una condición anatómica que aclara por qué un cirujano cristiano debía saber circuncidar. Y si el castrado era un hombre sin genitales, el hermafrodita -que situó entre las cirugías para los genitales masculinos y los femeninos - tenía dos. Para restaurar la feminidad y hacer a las mujeres sexualmente accesibles, el cirujano debía extirpar el tentigo, una estructura que después se conoció como nimphe y clítoris (McVaugh y Ogden, 1997, 49; Lewis y Short 1879; Du Cange 1883-87, t.8, col. 64c; Jacquart y Thomasset 1989, 33; Bullough 1994, 35; Lochrie 2005, 71-89; García Jáuregui 2010, 232; Moral de Calatrava 2005, 61; Moral de Calatrava 2007, 208; Moral de Calatrava 2013).

Céspedes afirmó que sus padres la reconocieron como mujer al tener sus auténticos genitales escondidos tras una piel y orinar de "modo femenino", pero el cirujano había descubierto el sexo escondido. La intervención que relató combinaba la cirugía para la mujer cerrada y la circuncisión porque, según Céspedes, Tapia realizó dos cortes: el primero era idéntico al que se hacía a las mujeres cerradas, pero en su caso escondía el pene y los testículos; la segunda incisión se practicaba en la circuncisión y corrigió la curvatura cortando el frenillo ${ }^{36}$. En principio, no era posible asignar un género a los hermafroditas, pero en el XVI, médicos, cirujanos y juristas rechazaron esta posibilidad. El 18 de julio, el fiscal volvió a interrogar a Céspedes sobre su potencia sexual y afirmó haber observado la norma heterosexual; mientras fue mujer utilizó su órgano femenino, pero después de la cirugía siempre se comportó como hombre. De hecho, dijo que tuvo un pene funcional con el "que orinaba por el como los demas hombres, porque estaba en el propio caño de la orina (...) y [por el] que tenía polucion en demasia"37. En otro de los textos que Céspedes tenía, el Compendio de la Humana Salud, Ketham afirmaba que médicos y sacerdotes debían asignar a un recién nacido hermafrodita un género y un nombre masculino porque, según Alberto Magno, "la natura siempre se esfuerça e entiende de condebir macho e nunca fembra, [y] como nombre mas digno e mas noble se deue nombrar por nombre de hombre"38. Pero los hermafroditas adultos teóricamente podían elegir, y reconocerse a sí mismos y ser socialmente identificados con un sexo y un género.

\footnotetext{
"E si se preguntasse si el hermofrodico deue responder en juyzio como hombre o como mujer. Responde se segun lo que requieren los drechos que ante que responda en juyzio deue ser interrogado e jurar de qual miembro vsa mas: e si del viril deue ser admeso como hombre: e si del feminil: deue ser admeso como mujer. E si de ambos a dos vsa: podria ser quemado por drecho" 39 .
}

Para los canonistas del XII y los teólogos del XVI, el problema del hermafroditismo gravitaba entorno a tres sacramentos: el bautismo, el matrimonio y el sacerdocio, porque para recibirlos era necesario identificar su sexo. Que en el coito fueran capaces de alternar los roles pasivo y activo por tener dos genitales vinculó culturalmente el hermafroditismo con la homosexualidad, y promovieron que eligieran una identidad de género que implicaba mantener un rol heterosexual excluyente o ser célibes (van der Lugt 2010, 111 y 113; DeVun 2015, 32). La relación y confusión cultural entre hermafroditismo, identidad sexual e inclinaciones eróticas se desarrolló bajo el amparo de teorías médicas que aglutinaban sexo y género en un mismo continuum. Supuestamente sólo los hermafroditas adultos podían elegir, y si uno se identificaba como hombre asumiría un papel sexual activo, pero debía plegarse a la pasividad si se reconocía como una mujer (Boswell 1980, 375-6; Nederman y True 1996, 510-1; Gilbert 2002, 3).

Céspedes sabía que era fundamental que hubiera sido sexualmente consistente y afirmó que, antes de estar en la cárcel de la Inquisición, tenía un pene apto para orinar y engendrar, y añadió que como hombre siempre había yacido con mujeres. La Inquisición interrogó a dos de sus anteriores parejas sexuales, pero sus testimonios terminaron por volverse en su contra. Según la medicina, la pareja debía expulsar al unísono 
el esperma para concebir y el varón tenía un orgasmo más intenso, pero la mujer disfrutaba el doble porque también recibía el semen viril ${ }^{40}$. La insatisfacción de esas dos mujeres confirmaba, para la Inquisición, que era una mujer. Isabel Ortiz, aquella que presentó una amonestación al matrimonio de Céspedes, corroboró lo que una testigo anónima había afirmado; que "no sentia que le hechasen simiente ensu vaso natural como suelen hazer los hombres, y ansi la dicha persona no tenia gusto en hecharse con el dicho eleno" ${ }^{41}$.

Aunque los médicos inquisitoriales eran inexpertos en hermafroditismo, inspeccionaron el cuerpo de Céspedes y refutaron sus argumentos en una declaración repleta de ciencia y tecnicismos. De acuerdo con la anatomía renacentista sostuvieron que las mujeres poseían testículos internos, pero negaron que alguna vez hubieran aflorado o que se hubiera operado, porque no quedaban cicatrices que lo probaran. Admitieron la posibilidad teórica de que a las mujeres les creciera una nimphe que podría confundirse con una verga, pero rechazaron que hubiese ocurrido en este caso por dos motivos: primero porque esta carne carecía de la fuerza necesaria para mantenerse erecta y penetrar a una mujer y, en segundo lugar, porque sería un miembro estéril incapaz de emitir fluidos como habían declarado las mujeres que se habían acostado con Eleno. Según los textos médicos, su pene no habría nacido en el lugar anatómico en el que "naçe el miembro viril a las mugeres hermafroticicas como todos los medicos y zurujanos diçen" ${ }^{\prime 2}$. Los testículos, el pene, la cirugía, la nimphe y las poluciones fueron calificadas una a una como embustes. Su esposa afirmaba que habían mantenido relaciones como marido y mujer, y la única explicación posible era que se hubieran ayudado de "algunos artificios como otras burladoras anhecho con baldreses y otras cosas"43. Pero la ausencia de genitales masculinos, cicatrices apropiadas y artefactos escondidos para corromper a su esposa no eran estrictamente pruebas. La evidencia definitiva sobre su auténtico sexo y género apareció durante el examen médico y les permitió certificar que Céspedes era una mujer.

“(...) dichos medicos y zirujano entraron al patio delas carceles donde fue trayda la dicha Elena de Çespedes, Alaqual vieron y miraron según les fue mandado. $Y$ bolbieron a la audiencia [y afirmaron que] es muger y que nunca fue hermafrodito ni tiene señales de ello, porque ser muger bese claro. $Y$ demas desto dice que pario y aunque hizo mediçinas para cegar y apretar que no pareçiese natura de muger, vino al cabo apareçer y romper sangre del menstruo que era detenido de antes" ${ }^{\prime 4}$.

\section{CONCLUSIONES}

Céspedes utilizó en su defensa la medicina y la filosofía natural y demostró comprender sus principios, pero era una explicación propia de otra época. Antes de que el tribunal dictara sentencia alegó por escrito que "al tiempo que me pretendi casar me caleçia". E preualesçia mas enel sexo masculino" ${ }^{\prime 46}$. Arguyó así que la transformación de mujer a hombre se debía a un calentamiento de la complexión general, que desplazó su naturaleza femenina y la masculinizó. Para apoyar esta afirmación utilizó un término infrecuente en castellano y latín, incalescens, una voz que aparece en el Digesto de Justiniano y el Decreto de Graciano para identificar el sexo de los hermafroditas (Green 2010, 163; Green 2013, 356). Ante la justicia civil de Ocaña afirmó que "de nacimiento salio cerrado de natura y sexo de manera que no se le echaba de ber el sexo que tenia mas de vno que por agujero por donde orinaba"47, y que tras la cirugía surgió un pene funcional. En definitiva, se presentó como un caso análogo al de Alberto Magno y compatible con la fisiología médica, pero sus argumentos eran medievales y los médicos de la Inquisición buscaron evidencias anatómicas propias de la ciencia del XVI (Molina 2016, 97).

Para la medicina renacentista, el hermafrodita neutro medieval ya no existía y Céspedes era, sin duda, una mujer porque había sido madre. Aunque afirmaba haber cumplido como hombre con distintas mujeres, el ausente miembro masculino ni había dado demostrado ser fecundo ni auténtico. La erudita defensa que Céspedes articuló fallaba porque, según la teoría médica de los humores y las complexiones, los hombres eran calientes, las mujeres frías y los hermafroditas neutros, y al calor de su parte masculina se le oponía la frialdad de su porción femenina. El calor y la frialdad dotaba a los hermafroditas de dos sexos anatómicos, pero esta oposición interna les hacía estériles. En el siglo XIII, Alberto Magno estableció en la Suma teológica que "hermaphroditus non generat" 48 , una incapacidad que se debía a "la inobediencia de las qualidades de las simientes, [de modo que] no puede hauer el macho complida perfeccion e entonces se mezcla la natura de la mujer e assi queda el hermofrodico impotente de ambas las partes" ${ }^{\prime 9}$.

Lo que la historiografía conoce como "El discurso de su vida" fue un ejercicio escolástico que demostraba su masculinidad (Karras 2004, 33). Describió la intervención quirúrgica, utilizó un vocabulario culto y técnico e insistió en sus múltiples relaciones con mujeres porque sabía de la importancia de haber elegido un sexo al presentarse como hermafrodita. 
Fue una defensa basada en los textos médicos que tenía en romance y que aceptaban la mutación femenina. Pero los peritos de la Inquisición rechazaron todos sus argumentos, negaron que las mujeres con nimphe pudieran penetrar a otra mujer y afirmaron:

\section{NOTAS}

1. Geronimo de Huerta, (1624) Historia Natural de Cayo Plinio Segundo, Madrid, Luis Sanchez, p. 262.

2. Agradezco al Dr. Lifante Pedrola haber Ilamado mi atención sobre este caso.

3. Francisco Diaz, (1575) Compendio de Chirurgia; enel qual se trata de todas las cosas tocantes a la theorica y pratica della, y de la anotomia del cuerpo humano, con otro breue tratado, de las quatro enfermedades, Madrid, Pedro Cosio, fol. $351 \mathrm{r}$

4. Ibid, fol. 353 r.

5. $3^{\text {er }}$ cuadernillo.

6. $3^{\text {er }}$ cuadernillo

7. 2o cuadernillo

8. $3^{\text {er }}$ cuadernillo.

9. $3^{\text {er }}$ cuadernillo.

10. 2 o cuadernillo.

11. $3^{\text {er }}$ cuadernillo

12. $1^{\text {er }}$ cuadernillo.

13. $1^{\text {er }}$ cuadernillo.

14. $~{ }^{\text {er }}$ cuadernillo. El énfasis es mío.

15. $3^{\text {er }}$ cuadernillo.

16. $3^{\text {er }}$ cuadernillo.

17. Alberto Magno (1200-1280) Questions on Animals. Eds. Irven Resnick M. y Kenneth F. (2008), Washington, The Catholic University of America Press, p. 336; Juan Gil de Zamora, (ca.1288) Historia naturalis. Eds. A. Domínguez García y L. García-Ballester (1994) Salamanca, Junta de Castilla y León, vol. 3, p. 1659

18. Cauliaco, Guido de (1498) Tratado de cirugía. Sevilla, Meinardo Ungut y Estanislao Polono. Eds. Ma T. Herrea y Ma E. González de Fauve (1997) Textos y Concordancias del Corpus Médico Español. Nueva York, Madison, fol. 24r.

19. Mundinus de Lentiis (1270-1326), Anatomia. Bolonia, de Haarlem H. y Walbeck, J., 1482, fol.18, col. b.

20. Damián Carbón, (1541) Libro del arte de las comadres o madrinas y del regimiento de las preñadas o paridas. Eds. Ma T. Herrea y Ma E. González de Fauve (1997) Textos y Concordancias del Corpus Médico Español. Nueva York, Madison, 1997, fol. 10r. La intención didáctica de Carbón para con las parteras ha sido puesta en duda. Cfr. (Moral de Calatrava 2007, 208-209; Moral de Calatrava, 2005, 55-64) "nacio y es muger. Y que como tal tiene todas las señales de muger. Que nunca asido hermafrodito, nien buena mediçina puede serque lo ayasido ni tenido miembro de hombre" ${ }^{150}$.

21. Ketham, Johannes de (1494) Compendio de la Humana Salud. Eds. Mạ T. Herrea y Mạ E. González de Fauve (1997) Textos y Concordancias del Corpus Médico Español. Nueva York, Madison, fol. 22v.

22. Ibid., fols. $11 v$, $20 \mathrm{r}$ y $21 \mathrm{v}$.

23. Bernardino Montaña de Monserrate, (1551) Libro de la Anothomia del Hombre. Valladolid, Sebastian Martinez. Eds. Ma T. Herrea y Ma E. González de Fauve (1997) Textos y Concordancias del Corpus Médico Español. Nueva York, Madison, fols. 52v y $62 r$

24. Ibid. fol. $86 \mathrm{v}$

25. Alberto Magno (1200-1280) De Animalibus. Ed. H. Stadler (1916-1920), Münster, Aschendorff, p.1226.

26. Lanfranco de Milan (1481) Chirurgia Magna. Eds. Mạ T. Herrea y Mạ E. González de Fauve (1997) Textos y Concordancias del Corpus Médico Español. Nueva York, Madison, fol. $100 \mathrm{v}$.

27. Según Covarrubias una sesma es la sexta parte de una vara (13,93 cm). Sebastián de Covarrubias, (1611) Tesoro de la Lengua castellana o española. Madrid, Luis Sánchez. En el siglo XIX todavía estaba en uso (de Paula Mellado 1845, 30).

28. El énfasis es mío.

29. 2o cuadernillo.

30. 2 cuadernillo.

31. $1^{\mathrm{er}}$ cuadernillo.

32. Bernardino Montaña de Monserrate, fol. 69r. (ver n. 23).

33. Anatomia Magistri Nicolai Physici (s.a.), Ed. G. W. Corner (1927) Anatomical Texts of the Earlier Middle Ages. A Study in the Transmission of Culture, Washington, Carnegie Institution of Washington, p. 85.

34. Lanfranco, 1481, fol. 100v. (ver n. 27)

35. Cauliaco 1498, fol. 160r. (ver n. 19).

36. Esta intervención puede identificarse actualmente con una frenuloplastia, una circuncisión y una frenectomía prepucial.

37. $3^{\text {er }}$ cuadernillo.

38. Ketham 1494, fol. 24r. (ver n. 22)

39. Ibid., fol. 24 r

40. Ibid. fol. 20v.

41. 2o cuadernillo.

42. $2 \circ$ cuadernillo. 
43. 2o cuadernillo.

44. 2o cuadernillo.

45. calentaba. Cfr. Alfonso X el Sabio (1275) General Estoria. Primera parte. Ed. P. Sánchez Prieto-Borja (2002) Alcalá de Henares, Universidad de Alcalá de Henares; Isaac Israelí (1450-1500) Tratado de las fiebres. Eds. Ma $\mathrm{a}$. Herrea y Ma E. González de Fauve (1997) Textos y Concordancias del Corpus Médico Español. Nueva York, Madison.

46. $3^{\text {er }}$ cuadernillo.

47. $1^{\text {er }}$ cuadernillo.

\section{BIBLIOGRAFÍA}

Asúa, Miguel de (2013), "War and Peace. Medicine and Natural Philosophy in Albert the Great". En: Resnick, Irven M. (ed.), A Companion to Albert the Great. Theology, Philosophy, and the Sciences, Leiden y Boston, Brill, pp. 269-297.

Barbazza, Marie-Catherine (1984), “Un caso de subversión social: el proceso de Elena de Céspedes (1587-1589)", Criticón, 26, [en línea] disponible en: http://cvc.cervantes.es/literatura/ criticon/PDF/026/026_019.pdf [consultado el 15/5/2017].

Barbazza, Marie-Catherine (2014), “Eleno/Elena de Céspedes: La construction d'une identité et ses aléas", Hispanismes, 3, pp. 41-57 [en línea], disponible en: http://www.hispanistes.org/images/PDF/HispanismeS/Hispanismes_3/SHF\%20 HispanismeS\%203\%20BARBAZZA\%20Marie-Catherine.pdf [consultado el 15/5/2017].

Beteta Martín, Yolanda (2009), "Representaciones de la sexualidad femenina en la literatura medieval y su influencia en la consideración de las mujeres", Arenal. Revista de Historia de las Mujeres, 16 (2), pp. 213-233, http://www.ugr. es/ arenal/articulo.php?id=136

Boswell, John (1980), Christianity, Social Tolerance and Homosexuality. Gay People in Western Europe from the Beginning of the Christian Era to the Fourteenth Century. Chicago y Londres, University of Chicago Press.

Brown, Judith C. (1986), Immodest Acts. The Life of a Lesbian Nun in Renaissance Italy, Oxford, Oxford University Press.

Brown, Judith C. (1990), "Sexualidad lesbiana en la Italia del Renacimiento: el caso de sor Benedetta Carlini". En: Amelang, James S. y Nash, Mary (eds.), Historia y Género: Las mujeres en la Europa Moderna y Contemporánea, Valencia, Institució Valenciana d'estudis i Investigació, pp. 167-176.

Bullough, Vern (1994), "On Being Male in the Middle Ages”. En: Lees, Clare A. (ed.), Medieval Masculinities. Regarding Men in the Middle Ages. Minneapolis y Londres, University of Minnesota Press, pp. 31-45.

Burshatin, Israel (1996), "Elena Alias Eleno. Genders, Sexualities, and "Race" in the Mirror of Natural History in SixteenthCentury Spain". En: Ramet, Sabrina Petra (ed.), Gender Reversals and Gender Cultures. Anthropological and Historical Perspectives, Londres y Nueva York, Routledge, pp. 105-122.

Burshatin, Israel (1999), "Written on the Body. Slave or Hermaphrodite in Sixteenth-Century Spain". En: Blackmore, Joshia
48. Alberto Magno (1200-1280) Summa Theologiae sive de mirabili sicientia dei. Ed. E. Borgnet, (1895), París, Bibliopolam editorem, Pars. II, tract. 13, q. 80, m2, p.116b; Pseudo-Alberto Magno (s.a.) Women's Secrets. A Translation of Pseudo-Albertus Magnus De Secretis Mulierum with Commentaries. Ed. Helen R. Lemay, (1992) Albany, State University of New York Press, p. 117.

49. Ketham 1494, fol. 24r. (ver n. 22).

50. 2을 cuadernillo. Subrayado en el original.

y Hutcheson, Gregory (eds.), Sexualities, Cultures, and Crossings from the Middle Ages to the Renaissance, Durham y Londres, Duke University Press, pp. 420-456.

Cadden, Joan (1993), Meanings of Sex Difference in the Middle Age. Medicine, science, and culture, Cambridge, Cambridge University Press.

Carrillo Esper, Raúl; Carrillo Córdova, Jorge Raúl; Carrillo Córdova, Dulce María y Carrillo Córdova, Carlos Alberto (2015), "Elena de Céspedes. La azarosa vida de una cirujana el siglo XVI", Gaceta Médica de México, 151, pp. 538-542, [en línea], disponible en: http://www.medigraphic.com/pdfs/gaceta/ gm-2015/gm154q.pdf [consultado el 12/05/2017].

Cleminson, Richard y Vazquez Garcia, Francisco (2009), Hermaphroditism, Medical Science and Sexual Identity in Spain, 1850-1960, Cardiff, University of Wales Press.

Cleminson, Richard y Vazquez Garcia, Francisco (2016), Sex, Identity and Hermaphrodites in Iberia, 1500-1800, Nueva York, Routledge.

Connell, Sophia M. (2000), "Aristotle and Galen on Sex Difference and Reproduction: A New Approach to an Ancient Rivalry", Studies in History and Philosophy of Science, Part A, 31(3), pp. 405-427.

DeVun, Leah (2015), "Erecting Sex: Hermaphrodites and the Medieval Science of Surgery", Osiris 30 (1), pp. 17-37, https://doi.org/10.1086/682954

Du Cange, (1883-1887), Glossarium mediæ et infimæ latinitatis. Niort, Lucien Favre, [en línea], disponible en : http://ducange.enc.sorbonne.fr/TENTIGO [consultado el 02/06/2017].

Eisenberg, Daniel (1990), "Spain". En: Dynes, Wayne (ed.), Encyclopedia of Homosexuality, Nueva York, Garland, pp. 1236-1243, [en línea], disponible en: http://users.ipfw. edu/jehle/deisenbe/encyclopedia/spain.pdf [consultado el 22/05/2017]

Fonahn, Adolf M. (1922), Arabic and Latin Anatomical Terminology Chiefly from the Middle Ages, Oslo, Kristiania, in commision by J. Dybwad, [en línea], disponible en: https:// archive.org/stream/arabiclatinanato00fonauoft\#page/n5/ mode/2up/search/concauitas [consultado el 02/06/2017].

Franco Rubio, Gloria A. (2012), "Metamorfosis femeninas y desafíos al patriarcado. El caso de Elena/Eleno Céspedes". En: 
Díaz Sánchez, Pilar; Franco Rubio, Gloria y Fuente Pérez, María Jesús (Coords.), Impulsando la Historia desde la Historia de las Mujeres. La estela de Cristina Segura, Huelva, Universidad de Huelva, pp. 417-427.

García Ballester, Luis (2001), La búsqueda de la salud. Sanadores y enfermos en la España medieval, Barcelona, Península.

García Jáuregui, Carlos (2010), La formación de la terminología médica en español (1493-1604) [Tesis doctoral], Salamanca, Universidad de Salamanca, [en línea], disponible en: https:// gredos.usal.es/jspui/handle/10366/76460 [consultado el 15 de julio de 2017].

Gilbert, Ruth (2002), Early Modern Hermaphrodites. Sex and other Stories, Nueva York, Palgrave.

Green, Monica H. (2008), Making Women's Medicine Masculine. The Rise of Male Authority in Pre-Modern Gynaecology, Oxford, Oxford University Press.

Green, Monica H. (2010), "Body Essences: Bodies as Categories of Difference". En: Kalof, Linda (ed.), A Cultural History of the Body in the Medieval Ages, Oxford, Berg, pp. 149-172.

Green, Monica H. (2011), "Moving from Philology to Social History: The Circulation and Uses of Albucasis's Latin Surgery in the Middle Ages". En: Glaze, Florence E. y Nance, Brian (eds.), Between Text and Patient: The Medical Enterprise in Medieval and Early Modern Europe, Micrologus' Library, 30, Florencia: SISMEL-Edizioni del Galluzzo, pp. 331-372.

Green, Monica H. (2013), "Caring for Gendered Bodies". En: Bennett, Judith y Karras, Ruth Mazo (eds.), Oxford Handbook of Medieval Women and Gender, Oxford, Oxford University Press, pp. 345-383.

Hessel, Stephen (2015), "Fashioning the Other, Fashioning the Self: The Inquisition v. Elena/o de Céspedes", Cincinnati Romance Review 39 (Fall), pp. 130-143, disponible en: http:// www.cromrev.com/volumes/vol39/complete.pdf [consultado el 20/04/2017].

Jacquart, Danielle y Thomasset, Claude (1989), Sexualidad y saber médico en la Edad Media, Barcelona, Labor.

Karras, Ruth Mazo (2004), "Using Women to Think with in the Medieval University". En: Mulder-Bakker, Anneke B. (ed.), Seeing and Knowing. Women and Learning in Medieval Europe 1200-1550, Turnhout, Brepols, pp. 21-33.

Lewis, Charlton T. y Short, Charles (1879), A Latin Dictionary, Oxford, Clarendon Press, [en línea] disponible en: http:// www.perseus.tufts.edu/hopper/text?doc=Perseus:text:199 9.04.0059:entry=tentigo [consultado el 02/06/2017].

Lochrie, Karma (2005), Heterosyncrasies. Female Sexuality When Normal Wasn't, Minneapolis y Londres, University of Minnesota Press.

Lugt, Maaike van der (2010), "Sex Difference in Medieval Theology a Canon Law: A Tribute to Joan Cadden", Medieval Feminist Forum, 46 (1), pp. 101-121, https://doi. org/10.17077/1536-8742.1854

MacLehose, William F. (2006), "Procreation and Ideas of Conception". En: Shaus, Margaret (ed.), Women and Gender in Medieval Europe. An Encyclopedia, Nueva York y Londres, Routledge, pp. 35-36.
Maganto Pavón, Emilio (2007a), El proceso inquisitorial contra Elena/o de Céspedes (1587-1588). Biografía de una cirujana transexual del siglo XVI, Madrid, Método Gráfico.

Maganto Pavón, Emilio (2007b), “La intervención del Dr. Francisco Díaz en el proceso inquisitorial contra Elena/o de Céspedes, una cirujana transexual condenada por la inquisición de Toledo en 1547", Historia de la Urología Española, 60 (8), pp. 873-86.

Martín Casares, Aurelia y Díaz Hernández, Magdalena (2016), "Nuevas reflexiones sobre "Elena, alias Eleno de Céspedes", transgénero, redes sociales y libertad en la España del siglo XVI". Bulletin for Spanish and Portuguese Historical Studies 41 (1), Article 2, https://doi.org/10.26431/0739-182X.1218

McVaugh, M. y Ogden, M.S. (1997), Guigonis de Cauliaco. Inventarium Sive Chirurgia Magna, Leiden, Nueva York y CoIonia, Brill, vol II.

Merisalo, Outi y Pahta, Päivi (2008), "Tracing the Trial of Transmission: The Pseudo-Galenic De Spermate in Latin". En: Goyens, Michéle; Leemans, Pieter de y Smets, An (eds.), Science Translated. Latin and Vernacular Translations of Scientific Treatises in Medieval Europe, Lovaina, Leuven University Press, pp. 91-104.

Molina, Fernanda (2015), "Juegos de artificios. Prácticas jurídicas y estrategias judiciales frente al fenómeno de la sodomía en la España moderna", Protohistoria, XVIII (24), pp. 43-68, [en línea] disponible en: http://www.redalyc. org/pdf/3801/380144016003.pdf [consultado el 15 de julio de 2017].

Molina, Fernanda (2016), “Disputas por la identidad. Representaciones sociales, discursos médicos y prácticas judiciales ante los fenómenos de ambigüedad sexual (España, siglos XVI-XVII)", Anales de Historia Antigua, Medieval y Moderna, 50, pp. 95-114, [en línea], disponible en: https://dialnet.unirioja.es/servlet/articulo?codigo $=6056960$ [consultado el 11 de julio de 2017].

Moral de Calatrava, Paloma (2005), "Damián Carbón y la instrucción de comadres en la España del siglo XVI". En: Flecha García, Consuelo; Núñez Gil, Marina y Rebollo Espinosa, Mạ José (eds.), Mujeres y Educación. Saberes, prácticas y discursos en la Historia, Miñano y Dávila, Buenos Aires y Sevilla, 2005, pp. 55-64.

Moral de Calatrava, Paloma (2006), "El aborto en la literatura médica castellana del siglo XVI", Dynamis, 26, pp. 39-68, https://dialnet.unirioja.es/servlet/articulo?codigo $=3333074$

Moral de Calatrava, Paloma (2007), "Magic or Science? What 'Old Women Lapidaries' Knew at the Age of Celestina", La Corónica 36 (1), pp. 203-235, https://doi.org/10.1353/ cor.2007.0017

Moral de Calatrava, Paloma (2008a), "El cuerpo del deseo. El discurso médico medieval sobre el placer sexual", Studium medievale, 1, pp. 135-147.

Moral de Calatrava, Paloma (2008b), La mujer imaginada. La construcción cultural del cuerpo femenino en la Edad Media. Murcia: Nausícaä.

Moral de Calatrava, Paloma (2009), "Sexo, Salud y Sacramento. Las relaciones sexuales y la salud de las mujeres en la 
Edad Media", Arenal. Revista de Historia de las Mujeres, 16 (2), pp. 235-262, https://www.researchgate.net/publication/261613785

Moral de Calatrava, Paloma (2013), “La «mujer cerrada»: La impotencia femenina en la Edad Media y el peritaje médicolegal de las parteras", Dynamis, 33 (2), pp. 461-483, https:// doi.org/10.4321/S0211-95362013000200009

Moure Casas, Ana (2008), "Plinio en España: panorama general", Revista de Estudios Latinos (RELat), 8, pp. 203-237, [en línea], disponible en: http://www.relat.org/relat/index.php/ relat/article/view/100 [consultado el 28 /04/2017].

Nederman, Cary J. y True, Jacqui (1996), "The Third Sex: The Idea of the Hermaphrodite in Twelve-Century Europe", Journal of the History of Sexuality, 6 (4), pp. 497-517, [en línea], disponible en: https://www.jstor.org/stable/pdf/4617219. pdf [consultado el 02/04/2017].

Paula Mellado, Francisco de (1845), España geográfica, Historia, Estadística y Pintoresca. Madrid, Mellado.

Puff, Helmet (2000), "Female Sodomy: The Trial of Katherina Hetzeldorfer (1477)", Journal of Medieval and Early Modern Studies, 30 (1), pp. 41-61, [en línea], disponible en: https:// read.dukeupress.edu/jmems/issue/30/1 [consultado el 12/04/2017].

Rolker, Christof (2014), "The two laws and the Three Sexes: Ambiguous Bodies in Canon Law and Roman Law $\left(12^{\text {th }}\right.$ to $16^{\text {th }}$ Centuries)", Zeitschrift der Savigny-Stiftung für Rechtsgeschichte. Kanonistische Abteilung, 100, pp. 178-222, https:// doi.org/10.7767/zrgka-2014-0108

Rosa Cubo, Cristina de la y Martín Ferreira, Ana I. (2016), “La sexualidad ambigua: un caso clínico heterodoxo en la obra de Amato Lusitano", eHumanista Conversos, 4, pp. 194-211. [en línea], disponible en: http://www.ehumanista.ucsb.edu/ sites/secure.Isit.ucsb.edu.span.d7_eh/files/sitefiles/conversos/volume4/12\%20ehumconv4.rosamartin.pdf [consultado el 18/05/2017].

Rosenthal, Franz (1978), "Ar-Râzî on the Hidden Parts", Bulletin of the History of Medicine, 52 (1), pp. 45-60.

Ruiz Rodríguez, Ignacio y Hernández Delgado, Alexander (2017), Elena o Eleno de Céspedes. Un hombre atrapado en el cuerpo de una mujer en la España de Felipe II, Madrid, Dykinson.

Siraisi, Nancy (1990), Medieval and Early Renaissance Medicine. An Introduction to Knowledge and Practice. Chicago y Londres, University of Chicago Press.

Vázquez García, Francisco (2011), “¿Por qué en la Edad Moderna no podía haber transexuales? Cuatro casos de transmutación sexual en España (siglos XVI-XX)". Ubi Sunt. Revista de Historia, 16, pp. 49-58, [en línea], disponible en: https:// dialnet.unirioja.es/revista/12304/A/2011 [consultado el 03/05/2017].

Vázquez García, Francisco y Richard Cleminson (2010), "Subjectivities in Transition: Gender and Sexual Identities in Cases of 'Sex Change' and 'Hermaphroditism' in Spain, c. 1500-1800", History of Science, XLVIII, pp. 1-38, https://doi. org/10.1177/007327531004800101

Velasco, Sherry M. (2011), Lesbians in Early Modern Spain, Nashville, Vanderbilt University.

Zamora Calvo, Ma Jesús (2008), "In virum mutata est. Transexualidad en la Europa de los siglos XVI y XVII", Bulletin hispanique, 110 (2), pp. 431-447, https://doi.org/10.4000/bulletinhispanique. 748 